\title{
UMA PROPOSTA DE APRENDIZAGEM BASEADA EM PROJETOS PARA AS DISCIPLINAS DE FÍSICA EXPERIMENTAL EM CURSOS DE ENGENHARIA
}

\author{
Sebastião Theodoro de Moura Neto - sebas.netofsa@gmail.com \\ Daniel Ordine Vieira Lopes - daniel.ordine@ifg.edu.br \\ Instituto Federal de Goiás - Câmpus Formosa \\ Rua 64, esq. c/ Rua 11, s/n, Expansão Parque Lago. \\ CEP: 73813-816. Formosa - GO.
}

Resumo: Apresentamos uma proposta para atividades práticas a serem realizadas nas disciplinas de Física dos períodos iniciais dos cursos de Engenharia orientada pela Aprendizagem Baseada em Projetos. As atividades aqui descritas têm o potencial de encorajar a criatividade, cooperação e engenhosidade dos estudantes, em oposição a metodologias tradicionais de laboratório que conduz os estudantes por etapas pré-estabelecidas.

Palavras-chave: Metodologias Ativas. Laboratório de Física. Ensino de Engenharia. Aprendizagem Baseada em Projetos.

\section{INTRODUÇÃO}

Os cursos de graduação em Engenharia possuem normalmente uma estrutura bem familiar. Os anos iniciais concentram as disciplinas de Física e Cálculo, que são responsáveis por boa parte das reprovações e consequentes evasões dos estudantes (FIORANI; LOPES; NAKAO, 2011). Um dos problemas apontados pelos discentes quanto às suas insatisfações com o curso está no excesso dessas matérias básicas, na visão dos estudantes alheias à prática da engenharia, e carência de disciplinas mais práticas, principalmente nesses anos iniciais dos cursos.

Em particular, as disciplinas de Física são muitas vezes apontadas responsáveis por boa parte da retenção e consequente evasão de estudantes nos cursos de engenharia (NEIVERTH; MACHADO; SCHNEIDER, 2015). A disciplina é vista como excessivamente teórica, com excesso de abstrações, e desconectada da realidade. Em nossa visão, parte dessa desconexão com a realidade apontada vem, entre outros fatores, de exemplos e problemas trabalhados em situações idealizadas, onde se chega a uma única resposta correta.

Onde supostamente o discente deveria ter um primeiro contato formal, acadêmico, com atividades práticas é no laboratório de física. No entanto, como apontamos abaixo, a realidade de muitos cursos é transformar o laboratório de física em simplesmente um processo de repetição de procedimentos pré-elaborados em equipamentos especialmente desenhados para aquele fim, deixando pouco espaço para a experimentação, a criatividade e o erro, processos importantes tanto para a compreensão de conceitos como para o desenvolvimento das habilidades desejadas em engenheiros.

Aqui apresentamos exemplos de como se transformar o laboratório de física para que atividades onde essas habilidades sejam exploradas, centrada no conceito de Aprendizagem 
Baseada em Projetos. O processo de elaboração das atividades envolve atenção do docente para adequar o tempo e dificuldade aos estudantes, atentando para o nível de conhecimentos prévios, o interesse por temas ou assuntos específicos.

\subsection{Importância do laboratório no ensino de Física no curso de engenharia}

A preocupação com o ensino de física não é algo recente e dentro dos estudos feitos a respeito do assunto é recorrente encontrarmos menções ao uso das aulas em laboratório como uma valiosa ferramenta de ensino. Guimarães (2009) afirma que a experimentação é uma estratégia importante para a criação de problemas reais, contextualizados e para estimular ações investigativas e questionadoras nos estudantes.

Hofstein e Lunetta $(2003,1982)$ afirmam que apesar de não sabermos com exatidão o quanto o laboratório consegue desenvolver a curiosidade nos estudantes, é razoável sugerir que um trabalho adequado pode ajudar a desenvolver essa característica nos alunos. Ainda nesse sentido os autores concluem que atividades apropriadas nos laboratórios podem promover o desenvolvimento de habilidades de questionamentos, solução de problemas, manipulação, observação, entendimento de conceitos científicos, cooperação e comunicação.

Para da Rosa (2003) o ambiente do laboratório promove discussão entre os alunos e pode estreitar a relação entre eles e o professor. Ela acrescenta que as atividades práticas proporcionam uma aproximação entre os conceitos que o estudante adquire no seu meio sociocultural e os conceitos científicos obtidos dentro do ambiente escolar. Outra conclusão importante de da Rosa é que a possibilidade de observação, análise, interpretação propiciadas por esse ambiente permitem a sustentação da aprendizagem, tornando essencial a inclusão dessa modalidade de ensino no processo educacional.

A importância do laboratório de física para os cursos de engenharia também fica evidente quando analisamos as habilidades que um engenheiro qualificado deve possuir. Análises do perfil do engenheiro buscado por empresas atualmente ou mesmo prospecções dos desafios necessários aos futuros engenheiros apontam que mais do que uma formação técnica especializada é importante que os novos engenheiros tenham também boas habilidades de comunicação, liderança, conduta ética, inteligência emocional, boa expressão oral e escrita, interdisciplinaridade e buscas por soluções novas para problemas até então desconhecidos (MARC J. RIEMER, 2007; NOSE; APARECIDA; REBELATTO, 2001; PÓVOA; BENTO, 2005). Essa preocupação com uma formação além dos conhecimentos técnicos especializados é explicitamente destacada nas novas diretrizes para os cursos de engenharia (BRASIL, 2019) no que se espera como habilidades dos egressos desses cursos.

Dentre os diferentes recursos didáticos disponíveis em um curso de engenharia, principalmente nos anos iniciais, o laboratório de física é fundamental para desenvolver nos estudantes algumas dessas habilidades que um profissional da área necessita. Não é sem motivo que o laboratório de física é obrigatório na maioria dos currículos dos cursos de Engenharia, portanto é crucial que se busque o máximo proveito dessa modalidade de ensino.

Apesar de ser amplamente defendido como um recurso didático importante, há ainda muitas críticas a como o laboratório de física é tradicionalmente utilizado. Uma das principais críticas ao uso do laboratório apontada por Borges (2002) para uma falta de relação mais direta entre as atividades e os conceitos físicos. O autor também menciona a própria visão dos alunos, que questionam a relevância dessas atividades já que o problema e o procedimento são previamente determinados por terceiros. Outro problema identificado é que a montagem de equipamentos, coleta de dados e cálculos demandam muito tempo, limitando a análise e discussões a respeito dos resultados, e que em geral os alunos percebem as atividades práticas como eventos isolados onde o objetivo é chegar à 'resposta certa'. Finalmente, o autor cita o 
fato de que os equipamentos usados no laboratório, além de caros, estão presentes apenas no próprio laboratório, distanciando esse ambiente e as experiências que o aluno possui fora dele.

Dessa forma, as aulas experimentais acabam se aproximando das aulas expositivas tradicionais já que ocorre uma hierarquização do saber. $\mathrm{O}$ aluno se limita ao papel reprodutor de fórmulas e procedimentos visando determinados resultados sem uma discussão mais profunda a respeito dos conceitos envolvidos e os resultados.

\title{
1.2 Metodologias ativas e Aprendizagem Baseada em Projetos
}

Alguns estudos vêm sugerindo a implementação de metodologias que promovem uma aprendizagem ativa. Essas metodologias são compostas por atividades que promovem um envolvimento maior do aluno com a disciplina. Barbosa e Moura (2014) afirmam para alcançar uma aprendizagem ativa "é essencial que o aluno faça uso de suas funções mentais de pensar, raciocinar, observar, refletir, entender, combinar, dentre outras que, em conjunto, formam a inteligência." (Ibid., p.1). É justamente esse tipo de atitude ativa da inteligência que essas novas metodologias buscam estimular no aluno, em contraposição a uma atitude passiva dos métodos tradicionais.

Barbosa e Moura (2014) afirmam que com o uso dos métodos ativos os alunos são capazes de assimilar maior volume de conteúdo, reter informações por mais tempo e aproveitam as aulas com mais satisfação e prazer. Também apontam algumas das capacidades que os alunos podem desenvolver através desses métodos:

Os alunos que vivenciam esse método adquirem mais confiança em suas decisões e na aplicação do conhecimento em situações práticas; melhoram o relacionamento com os colegas, aprendem a se expressar melhor oralmente e por escrito, adquirem gosto para resolver problemas e vivenciam situações que requerem tomar decisões por conta própria, reforçando a autonomia no pensar e no atuar. (Ibid., p.3).

A partir disso, podemos afirmar que a utilização desses métodos nas disciplinas de Física, especialmente no Laboratório, é muito bem-vinda não apenas para a própria disciplina, mas também para os cursos de Engenharia como um todo.

Barbosa e Moura (2014) definem projetos como "empreendimentos finitos com objetivos bem definidos e nascem a partir de um problema, uma necessidade, uma oportunidade ou interesses de uma pessoa, um grupo de pessoas ou uma organização." (Ibid., p.4) A elaboração e execução de projetos é uma realidade muito presente dentro da vida acadêmica de um estudante de engenharia, e não será diferente durante sua carreira profissional. Os autores também destacam que:

\begin{abstract}
Diversas publicações e experiências na área de educação tecnológica referemse ao potencial dos projetos de aprendizagem (também chamados de projetos de trabalho) como contribuição de alto valor para o processo educativo [...] especialmente no que diz respeito à promoção de uma aprendizagem significativa, em contraposição à aprendizagem tradicional do tipo verbal, retórica, livresca, de ênfase teórica e descontextualizada." (Ibid., p.4).
\end{abstract}

Barbosa e Moura (2014) também afirmam que as características dessa metodologia são de grande valor e interesse para o ensino de engenharia. Nesse tipo de metodologia são apresentados projetos a serem desenvolvidos de acordo com uma determinada finalidade, divididos em três categorias: explicativo (ou didático), Construtivo e Investigativo.

No projeto do tipo explicativo os alunos são estimulados a explicar o funcionamento de aparelhos tecnológicos (preferencialmente em contato direto), analisando suas partes, se 
familiarizando com os conceitos científicos necessários para compreensão do aparelho. Já no projeto do tipo construtivo os alunos devem construir um equipamento que possua uma função específica. Barbosa e Moura recomendam esse tipo de projeto para alunos mais avançados no curso, mas aqui apresentaremos justamente propostas de projetos do tipo construtivos nos períodos iniciais do curso. O tipo investigativo reproduz uma investigação científica de longo prazo mais rigorosa, desde a colocação da questão a ser investigada.

\section{PROPOSTA DIDÁTICA DE PROJETOS}

Diante do exposto, apresentamos a partir de agora uma proposta pedagógica para o laboratório de física dentro do contexto de uma metodologia ativa. A proposta aqui apresentada deve necessariamente estar integrada às atividades em sala de aula com o estudo formal dos conceitos, discussão de exemplos reais e problemas e sempre que possível trabalhar em sala problemas ricos em contexto. Essa modalidade se refere a problemas que descrevem situações com um problema real que deve ser solucionado, preferencialmente por grupos de estudantes, utilizando os conceitos e exercícios trabalhados em aula (ver Quadro 1).

Quadro 1: Exemplos de exercícios ricos em contexto sobre o assunto equilíbrio e torque, realizado pelos estudantes em grupo durante o curso de Física 2.

Você vai visitar parentes na roça, e decide ajudar a transportar água de um poço para a casa. Para poupar tempo, utilizando seus conhecimentos de engenharia, você desenvolve um equipamento para transportar 3 baldes de uma vez, utilizando somente um só braço (o que permitiria, em princípio, transportar 6 baldes por viagem). A ideia é utilizar varas resistentes de 1,5 metro que você encontrou jogada num canto. Com um arame, você pendura 3 baldes nessa vara: o primeiro exatamente em uma extremidade e os outros dois separados por distâncias de $30 \mathrm{~cm}$ ao longo da vara (ou seja, a 30 e 60 $\mathrm{cm}$ da extremidade do primeiro). Então você apoiaria a vara no ombro, deixando os baldes para trás de você, e com uma das mãos seguraria a outra extremidade da vara. Sabendo que, nessa configuração, sua mão e seu ombro ficarão a uma distância de aproximadamente meio metro horizontalmente ao longo da barra, faça os cálculos para verificar a viabilidade desse projeto (isso é, se você conseguiria suportar). Os baldes pesam cada um $300 \mathrm{~g}$ e têm capacidade para 8 litros. A massa da barra é de $0,5 \mathrm{~kg}$. Aproximações são bem-vindas.

Você conseguiu um emprego de férias trabalhando em Brasília lavando janelas de hotéis de luxo (eles pagam bem e possuem plano de saúde). A plataforma que você e seu parceiro estão usando para chegar às janelas possui largura de 1 metro e comprimento de 4 metros. Das várias vezes que você precisou colocar e tirar a plataforma da caminhonete você sabe que ela tem uma massa de $70 \mathrm{~kg}$. É apoiada por dois cabos, um em cada ponta, montada de forma a evitar que a plataforma gire à medida em que é içada pelo exterior do prédio à velocidade constante. Se você (massa de $55 \mathrm{~kg}$ ) está em pé na plataforma a 1 metro de um dos cabos e seu parceiro (massa de $87 \mathrm{~kg}$ ) está a 1,30 metros do outro cabo e ambos estão a meio metro das laterais, qual é a tensão em cada cabo? Suponha que a plataforma possui uma distribuição uniforme de massa e uma espessura desprezível.

\section{Fonte: dos autores}

Como mencionado na introdução, a parte de laboratório das disciplinas de Física muitas vezes conduz os estudantes por um roteiro pré-definido no qual há pouco ou nenhum espaço para que o estudante apresente seus próprios questionamentos ou busque sua própria maneira de responder a pergunta-objetivo daquele experimento. Mostramos como exemplo o roteiro apresentado na Figura 1, onde cada detalhe é minuciosamente especificado, até mesmo as distâncias colocadas no experimento, sem que haja espaço para que o estudante aprenda errando. Esse estilo de roteiro para as práticas de laboratório de física é extremamente comum, ao ponto de ser o padrão, em diversas instituições de ensino. Ao invés disso, propomos 
experimentos na qual um problema ou questão-problema era apresentada e o grupo de estudantes tinha que buscar como resolvê-la utilizando quaisquer instrumentos, disponíveis ou não no laboratório.

Figura 1: Trecho de um roteiro pré-definido típico de laboratório de física.

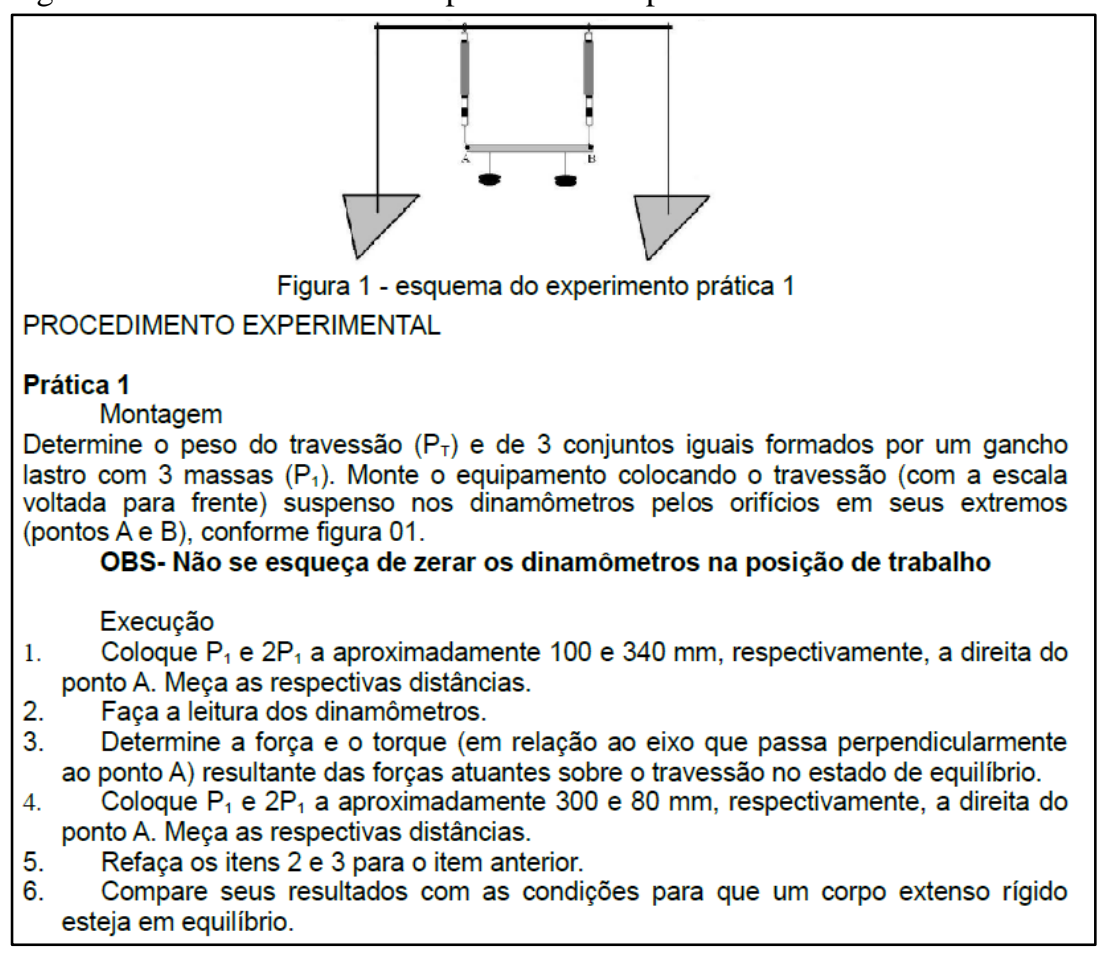

Fonte: Unicentro. Roteiros disponíveis online (UNICENTRO, 2020)

Para ilustrar a proposta, usamos o tema equilíbrio de corpo extenso e torque, normalmente trabalhado no final da disciplina Física 1 ou início de Física 2. Destacamos que esse assunto é fundamental para diversas outras disciplinas ao longo de todo o curso de engenharia civil, então deve ser dada a devida importância nos períodos iniciais. Na figura 1 apresentamos uma situação-problema trabalhada em sala. Os alunos buscam, com os conceitos aprendidos durante as aulas, solucionar em grupos o problema. A solução (muitas vezes mais de uma solução é possível, devido às diferentes considerações ou aproximações feitas pelos alunos) é então apresentada e discutida. Os detalhes da elaboração dessas situações-problema não são o foco deste trabalho, mas deixamos parte da literatura que as embasa conceitual e metodologicamente (HELLER; HELLER, 2010).

Após esse momento em sala de aula vamos ao laboratório, onde uma nova atividade é apresentada (Quadro 2). Dessa vez, ao invés da solução matemática, em folha de papel, é pedido aos alunos que realizem uma tarefa, que pode ser construir um modelo de algo, realizar alguma medição específica, descrever em detalhes alguma situação ou fenômeno ou tentar verificar algum princípio físico. No exemplo do quadro 2, um móbile (como de berço de bebê) seguindo alguns critérios como número mínimo de peças. É também exigido dos alunos um relatório que descreva em detalhes o que foi feito, utilizando os conceitos aprendidos.

Destacamos a diferença dos roteiros prontos comumente trabalhados nas disciplinas de Física. Nesses, os estudantes quase não têm liberdade de explorar suas próprias soluções e, como relatado por Borges (2002), os alunos repetem mecanicamente os passos para obter a resposta esperada pelo professor. No problema aqui proposto, há liberdade na escolha dos 
materiais, na forma de execução e não há uma exigência da resposta correta. Ao invés de "comprovar as equações de equilíbrio" utilizamos "verificar se elas [as condições de equilíbrio] são satisfeitas ou não". A motivação para essa substituição é que em situações reais erros de execução, montagem, medida, assim como atritos e outras forças negligenciadas podem afetar o resultado que é esperado quando estamos acostumados com problemas idealizados de livrotexto.

Quadro 2: Trecho da tarefa referente ao tópico "equilíbrio de corpo extenso e torque".

\begin{abstract}
Móbile
Em grupos de até 4 pessoas, vocês devem montar um móbile de no mínimo duas hastes (sugestão de material: régua escolar, borracha, barbante, ripas de madeira, linha de costura).

O relatório deve conter uma foto do móbile em equilíbrio e uma representação simplificada desse mesmo móbile, identificando as distâncias e outras grandezas importantes além da descrição de sua composição e funcionamento. Se não tiverem acesso a balança, podem fazer essa medida na semana que vem.

Então vocês devem calcular as equações de equilíbrio e verificar se elas são satisfeitas ou não. 1 ponto será perdido se não houver tratamento e propagação de erros.
\end{abstract}

Fonte: os autores. Disponível no Moodle da disciplina

Enfatizamos também que a maior liberdade na execução do experimento ou protótipo em termos dos métodos e materiais e consequentemente da análise realizada não significava um menor rigor na exigência técnica. Relatórios técnicos do que era desenvolvido pelos estudantes eram exigidos, escritos seguindo estruturas comuns do ambiente acadêmico (resumo, objetivo, introdução teórica, materiais e métodos, resultados e discussão, e conclusão), exigindo também o correto tratamento de erros, e até a elaboração do relatório utilizando o sistema de escrita LaTeX (LATEX, [s.d.]), familiarizando os estudantes com a utilização de códigos e conceitos de lógica computacional.

Na Figura 2 apresentamos trecho de um dos relatórios entregues por um dos grupos. É interessante notar que o relatório contém descrição de problemas e dificuldades encontrados durante a execução da tarefa, normalmente ausentes nos relatórios de roteiros padronizados onde não se deixa espaço para que erros sejam cometidos. Essa abordagem estimula a criatividade desejada de engenheiros e mostra o processo de inovação e criatividade como um processo com mais dificuldades que sucessos. Além disso, incentivam a cooperação e organização entre estudantes de um mesmo grupo, e eventualmente de outros grupos que estão realizando tarefas similares, mas não idênticas. Acreditamos que esses projetos podem também ajudar a conter a evasão nos cursos de engenharia pois, como apontado por alguns autores (ver por exemplo (FIORANI; LOPES; NAKAO, 2011) um dos motivos para a insatisfação com o curso de engenharia civil é o excesso de matérias teóricas com pouca aplicação para a prática profissional em engenharia. O relatório mostrado aqui foi elaborado utilizando o sistema de escrita LaTeX. 


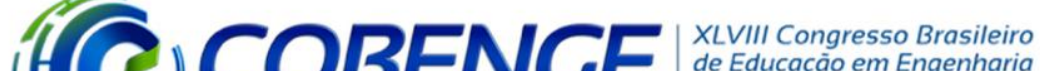 (C) COBENCE 2020 III Simpósio Internacional de Educaçāo em Engenharia da ABENGE}

Figura 2. Trecho de relatório entregue referente ao projeto do Móbile da figura 3. Incluímos também o diagrama feito pelos alunos e a foto do móbile construído, também presentes no relatório.

\section{Construção do móbile}

A construção de um móbile foi realizado com o objetivo de nos ajudar a conhecer, na prática, o que faz. com que um objeto permaneca estável na presença de forças. onde os torques deverão estar em perfeito equilíbrio, para que o móbile possa funcionar corretamente. O desenvolvimento do móbile foi realizado em 5 etapas: escolha do material ideal, realização de cálculos, montagem, propagação de erro e conclusão.

\subsection{Escolha do material}

Logo após o professor nos passar essa tarefa, o nosso grupo reuniu, onde foi discutido qual material deveria ser utilizado. e por votacão unanime foi decidido ane deveria ser feito com PVC por ser leve e fácil de ser trabalhado. Depois escolhemos que essas barras seriam fixados por pequenos ganchos e linha de pesca, esta por ser quase transparente daria um efeito legal. O restante do material foi escolhido ao longo dos trabalhos. Na tabela 1 abaixo está a relação dos materiais e ferramentas utilizadas.

\begin{tabular}{|l|l|}
\hline Quantidade & Materiais e Instrumentos \\
\hline $0,75 \mathrm{~m}$ & PVC $25 \mathrm{~mm}$ \\
9 & gancho pequeno \\
$1,5 \mathrm{~m}$ & linha de pesca $0,20 \mathrm{~mm}$ \\
$2 \mathrm{~kg}$ & chumbada de pesca \\
1 & balança digital de cozinha \\
1 & trena \\
1 & serrinha \\
\hline
\end{tabular}

Tabela 1: Materiais e instrumentos utilizados

\subsection{Montagem do módulo}

Como já tínhamos os pesos dos objetos e das barras, as distâncias que os ganchos ficariam da extremidade e do ponto de equilíbrio foi só colocarmos isso em prática. Primeiro cortamos a barra de Pve, ficando com $25 \mathrm{~cm}$ cada uma, depois fixamos os ganchos nas distâncias predeterminadas. Posteriormente veio a parte que exigia mais paciencia que era pendurar os pesos (chumbadas) com a linha de pesca nas barras. Colocamos inicialmente o peso $\mathrm{F} 1=0.0687 \mathrm{~N}(\mathrm{~m}-7 \mathrm{~g})$ que já tínhamos fixado, depois para equilibrarmos a barra $\mathrm{B} 1$, colocamos o P2 com mesma massa que tínhamos calculado na equação 4 , a massa de 45,4g, porém ela conseguiu a estabilidade com $44 \mathrm{~g}$ pesados na balança de cozinha. Na barra B2 o equilíbrio foi atingido com a massa no $\mathrm{F} 4$ de $259 \mathrm{~g}, 0,7 \mathrm{~g}$ a mais do que tínhamos calculado na equação 6 . Já na barra B3 o erro foi um pouco maior, pois colocamos uma massa de $995 \mathrm{~g}$ para atingir o equilibrio, contudo, a massa que estava previsto era de $943,46 \mathrm{~g}$ como se vê, na equação 8 . Na figura 3 , em anexo, esta a imagem do móthile montado e em emuilihrio

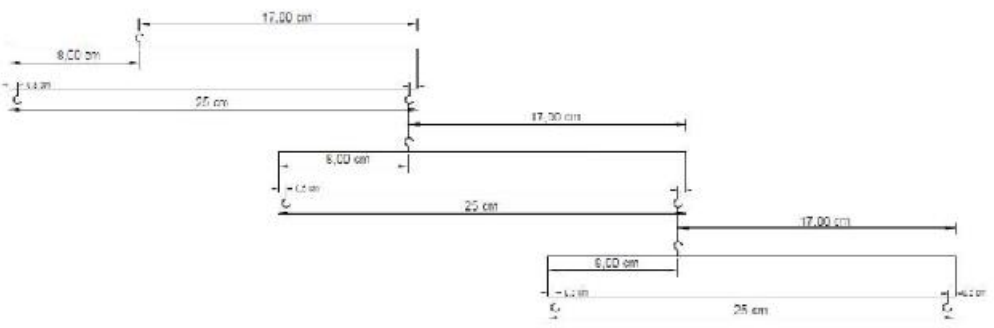

Figura 2; estrutura com as cotas

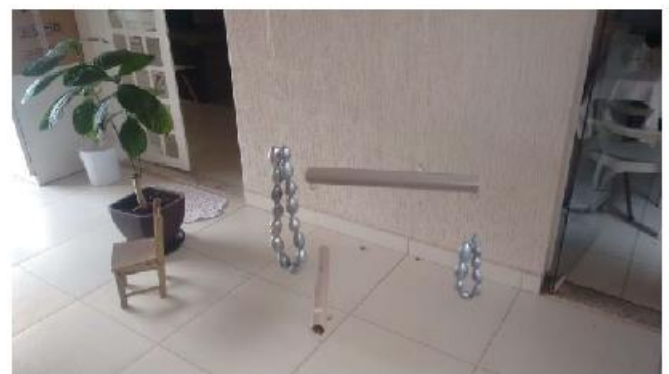

Figura 3: móbile pronto equilibrado

Fonte: Relatório entregue por estudantes no Moodle da disciplina 
Outros projetos desenvolvidos dentro da categoria construtiva exigiam um planejamento um pouco maior.

- Guindaste: foi pedido a construção de um guindaste que pudesse erguer algum peso. A escolha dos materiais, a mecânica para erguer o peso (e a capacidade), o tamanho e qualquer outra característica ficando totalmente por conta dos estudantes. Além da execução do equipamento, era pedido também a descrição das forças e torques presentes na estrutura, identificando os pontos de maior tensão e tração. Para estimular os estudantes, era organizada uma mostra pública no pátio da instituição, com uma premiação simbólica para os guindastes mais criativos ou interessantes.

- Montanha-Russa: os estudantes deviam construir uma montanha-russa para bolinha de gudes seguindo algumas especificações (número mínimo de subidas, altura máxima e tempos máximos e mínimo do percurso completo da bolinha). Também era realizada uma competição para premiar a montanha-russa que melhor se aproximasse de um percurso de 30 segundos. $\mathrm{O}$ material e detalhes também ficava a critério dos grupos. O momento da competição era usado para discussões sobre conservação de energia, trabalho e atrito.

- Estação Espacial: a construção de uma maquete e explicação teórica de uma estação espacial que consiga simular gravidade em seu interior a partir de forças centrífugas. Era exigido um memorial descritivo explicando a planta da estação, seus espaços, a escolha dos materiais, a energia necessária para colocá-la em órbita e a energia necessária para colocá-la na rotação necessária para simulação de gravidade.

- Lançador balístico: O desenvolvimento um lançador de qualquer objeto (não-letal) utilizando molas e/ou elásticos. Era exigido que fossem feitos os cálculos para prever o alcance do projétil em função da deformação do objeto elástico.

A elaboração das regras, critérios e ideias gerais para esses projetos deve ser cuidadosamente pensada, avaliando o nível de conhecimento prévio dos estudantes, seus interesses e o tempo disponível para a realização do projeto.

Além desses projetos construtivos, propomos também projetos um pouco similares às atividades dos roteiros pré-definidos, onde há um conceito físico específico a ser verificado, mas com mais liberdade que nos roteiros como o da Figura 1. Como os estudantes não precisam definir um objeto de pesquisa e realizar uma longa investigação do tema, não podemos classificar essas tarefas como Projetos Investigativos no sentido apontado por Barbosa e Moura (2014). Assim chamaremos essas atividades de "tarefas investigativas simples", pois a questão a ser investigada já está colocada e há até a sugestão de equipamentos a serem utilizados. A elaboração dos detalhes da experiência caberá ao aluno. Exemplos desses projetos estão mostrados no Quadro 3.

Quadro 3: Exemplos de tarefas investigativas simples

\section{Coeficiente de Atrito}

Crie uma maneira eficaz e de baixo custo de medir o coeficiente de atrito estático e cinético entre um objeto de sua escolha e ao menos três superfícies diferentes.

\section{Transformação de Energia Mecânica}

Sugestão: bolas de gude ou carrinhos de brinquedo, canos, tábuas, etc

Monte um experimento de sua escolha que permita mostrar a conservação da energia mecânica (potencial+cinética) usando apenas um cronômetro e uma calculadora. Por exemplo uma rampa 
com marcações de altura e de deslocamento (para que possamos medir o tempo e calcular a velocidade). Se não houver conservação da energia mecânica, explicar os motivos.

\section{Intensidade Sonora}

Emitindo um som constante com uma caixa de som, verifique, utilizando um medidor de intensidade sonora, se de fato a intensidade cai com o inverso do quadrado da distância. Faça o teste em ambientes fechados e abertos, e disserte sobre as diferenças observadas (se houver alguma).

Fonte: dos autores

Os relatórios produzidos pelos estudantes apresentavam, assim como os mostrados nas Figuras 2 e 3, diferentes montagens, execuções e análises. Discutiam também diferentes problemas encontrados durante a realização da tarefa. Essa abordagem incentiva a criatividade, a dúvida, e estimula a aceitar os erros e falhas como parte do processo de aprendizagem.

\section{CONSIDERAÇÕES FINAIS}

Apresentamos aqui exemplos de como utilizar Aprendizagem Baseada em Projetos nas atividades de laboratório das disciplinas de Física nos cursos de engenharia civil. Defendemos que essa abordagem, ao contrário dos roteiros de prática laboratorial pré-definidos frequentemente utilizados nessas disciplinas, encoraja a curiosidade, criatividade e inovação na resolução de problemas, habilidades desejadas para os futuros engenheiros. A proposta também se alinha às Diretrizes Curriculares Nacionais para cursos de engenharia.

Os desafios para o docente que planeja implementar essa metodologia são, além do cuidado em preparar os projetos e tarefas, a maior necessidade de acompanhamento e retorno aos estudantes durante a execução dos projetos, e prezar por uma avaliação dos trabalhos que dê mais valor ao processo (medições corretas, análises cuidadosas) do que a resposta esperada.

\section{REFERÊNCIAS}

BARBOSA, Eduardo Fernandes; DE MOURA, Dácio Guimarães. Metodologias ativas de aprendizagem no ensino de Engenharia. In: XIII International Conference on Engineering and Technology Education, 2014, Guimarães, Portugal. Anais. Guimarães, Portugal

BORGES, Antônio Tarciso. Novos rumos para o laboratório escolar de ciências. Caderno Brasileiro de Ensino de Física, Florianópolis, SC, v. 19, n. 3, p. 9-31, 2002.

BRASIL. Ministério da Educação. Conselho Nacional de Educação. Diretrizes Curriculares Nacionais do Curso de Graduação em Engenharia (DCNs de Engenharia). 2019, 1, p. 109.

DA ROSA, Cleci Werner. Concepções teórico-metodológicas no laboratório didático de física na universidade de Passo Fundo. Ensaio Pesquisa em Educação em Ciências, Belo Horizonte, v. 5, n. 2, p. 94-108, 2003.

FIORANI, Lucas A.; LOPES, Marilia P. G.; NAKAO, Osvaldo S. Evasão na Engenharia Civil da Escola Politécnica da USP: o que pensam alunos e professores. In: XXXIX Congresso Brasileiro de Ensino de Engenharia, 2011, Blumenau, SC. Anais. Blumenau, SC 
GUIMARÃES, Cleidson Carneiro. Experimentação no Ensino de Química: Caminhos e Descaminhos Rumo à Aprendizagem Significativa. Química Nova na Escola, [S. l.], v. 31, n. 3, p. 198-202, 2009.

HELLER, Kenneth; HELLER, Patricia. Cooperative Problem Solving in Physics A User's Manual. 2010. Disponível em: https://www.aapt.org/Conferences/newfaculty/upload/CoopProblem-Solving-Guide.pdf. Acesso em: 1 jun. 2019.

HOFSTEIN, A. V. I.; LUNETTA, Vincent N. The Laboratory in Science Education : Foundations for the Twenty-First Century. Science Education, [S. l.], v. 88, n. 1, p. 28-54, 2004.

HOFSTEIN, Avi; LUNETTA, Vincent N. The Role of the Laboratory in Science Teaching: Neglected Aspects of Research. Review of Educational Research, [S. l.], v. 52, n. 2, p. 201$217,1982$.

LATEX. The LaTeX Project. [s.d.]. Disponível em: https://www.latex-project.org/. Acesso em: 26 jul. 2020.

MARC J. RIEMER. Communication Skills for the 21st Century Engineer. Global Journal of Engineering Education, [S. l.], v. 11, n. 1, p. 89-100, 2007.

NEIVERTH, Cristhiane Anete; MACHADO, Marina de Lurdes; SCHNEIDER, Fábio Alencar. O processo de ensino aprendizagem das disciplinas de Física e Cálculo nos cursos de engenharia: uma Análise do tema nas publicações científicas no período de 2008 - 2015. In: EVINCI UNIBRASIL 2015, Curitiba, PR. Anais. Curitiba, PR

NOSE, Michelle Mike; APARECIDA, Daisy; REBELATTO, Nascimento. O perfil do engenheiro segundo as empresas. In: XXIX Congresso Brasileiro de Ensino de Engenharia, 2001, Porto Alegre, RS. Anais. Porto Alegre, RS

PÓVOA, J. M.; BENTO, P. E. G. O engenheiro, sua formação e o mundo do trabalho. In: XXXIII Congresso Brasileiro de Ensino de Engenharia, 2005, Campina Grande, PB. Anais [...]. Campina Grande, PB

UNICENTRO. Roteiros. 2020. Disponível em: https://www2.unicentro.br/fisica/roteiros/. Acesso em: 25 jul. 2020.

\section{A PROPOSAL FOR PROJECT BASED LEARNING ACTIVITIES IN PHYSICS LABORATORY IN ENGINEERING COURSES}

Abstract: We present a proposal for practical activities developed in physics courses in the freshmen years of engineering education oriented by Project Based Learning. The activities here described have the potential to encourage students creativity, cooperation and ingenuity, in contrat to traditional methods at physics laboratories that carry students through predetermined steps.

Keywords: Active methodologies. Physics Laboratory. Project Based Learning. 